\title{
Telling About Engagement Is Not Enough: Seeking the "Ethics" of Ethics Consultation in Clinical Ethics Case Reports
}

\author{
Kelly Armstrong
}

\section{Introduction}

"The Zadeh Scenario," a wondrously rich narrative generously shared by Finder, walks the reader through the interactions of an ethics consultant during a case. In this telling, Finder appears deeply cognizant of how memories can be affected by subsequent decisions and experiences. Hence, it is important to note that many key parts of the narrative - if not all of it - were captured concurrently or in close proximity to the actual events, thereby revealing the factual and normative obscurity that unfolds over the course of an ethics consultation. Finder's polished skills of careful attention and mindful appreciation in recounting the "doing" of an ethics consult thus provide something of an anthropological account - telling us who went where and the content of several weighty conversations - rather than what might traditionally be expected from an ethical analysis of a case presentation.

Importantly, though, this accounting exposes the difficulty of abstracting moral understanding from a description of the actions of the involved parties. At the same time, the narrative also reveals an important limitation of case presentations, namely that they are generally presented as a concrete case in time with a firm beginning and end. For all its richness, much of the information that is needed to assess what is ethically important or problematic in the consult falls outside of the scope of the narrative we have before us. This deficiency may partly lie in the fact that like many ethics consults, the ethics consult in which Finder finds himself has an unclear beginning - did it begin 3 years ago when an ethics consult was called by the neurologist; did it begin during subsequent hospitalizations when Dr. Moore was approached by concerned individuals involved in Mrs. Hamadani's care; did it begin

K. Armstrong $(\bowtie)$

Center for Clinical and Organizational Ethics, Virginia Commonwealth University School of Medicine Inova Campus, Falls Church, VA, USA

e-mail: kelly.armstrong@inova.org 
during this hospitalization when Dr. Broukhim requests the consult from Dr. Finder's ethics colleague, Dr. Moore; or did it begin when Mr. Zadeh approached Dr. Finder outside the hospital? Moreover, is Finder picking up where Dr. Moore left off, or is he in some way beginning the consultation anew alongside the new relationship he seeks to establish with Mrs. Hamadani's family? The narrative of "The Zadeh Scenario" is not clear on this point, but it is an important issue to consider as we consider the activities of the ethics consultation we have before us.

\section{Preparatory Elements of a Consult}

After Mr. Zadeh approaches Dr. Finder outside of the hospital passionately explaining that his family no longer wants to interact with Dr. Moore or even have Dr. Moore check in on the patient, one could have expected the narrative to turn to a discussion of the difficult ethical implications of carrying out an institutional ethics consultation without the involvement of the patient or her family. Finder acknowledges that he didn't think it was "appropriate to force family members to talk with ethics consultants even if we continue to meet with members of the patient care team" (Finder 2018: 26). Yet, he begins preparing for what "was looking to be a very interesting consultation" (Finder 2018: 29), assigning the role of ethics support for staff and other care providers to Dr. Moore while preparing to take over the consultation with Dr. Broukhim and the family himself. Unfortunately, the rationale for this move is never fully explained in the narrative. Was the family saying they did not consent to the ethics consultation process, or merely saying that they no longer wanted to speak with Dr. Moore? This is an important distinction with wider implications regarding the goals of ethics consultation, issues of consent, and the dual role of ethics consultation in the care of patients and in supporting the processes of the institution.

As Finder prepares to take over the consultation, the narrative illustrates many important elements of preparation that are critical to a successful consultation process. Before any analysis or clarification can begin, the specific details of the case frame the issues and diligent research of the medical record along with conversations with care providers provide a necessary understanding of the clinical, contextual and social factors that ground important values expressed by the patient, family and caregivers. Thus, it is important that we see Finder begin his participation in the consultation process by pulling up the patient's electronic medical records to better understand what had been happening not only medically, but also in regard to the social dynamics surrounding Mrs. Hamadani's care. Only after this grounding does he call the original consultant on the case, Dr. Moore, to discuss Dr. Moore's understanding of what had happened during this and previous hospitalizations. The conversation touched upon not only Mrs. Hamadani's medical situation, but also important information from Dr. Moore's conversations and interactions with her family, her physicians, and the nursing staff. Significantly, we also see Dr. Moore's analysis of those interactions in regards to their emotional content and the perceived motivations of the persons involved in those specific interactions. 
Before going to the Unit, and thus making his presence known as a person now involved in the patient's case, Finder notifies the attending physician, Dr. Broukhim, that both he and Dr. Moore were now involved in Mrs. Hamadani's case. This is appropriate for a number of reasons. The initial request for ethics assistance did not come from the patient or family, where it may be appropriate to first speak with the requestor of ethics assistance to determine the nature of the ethical question or issue. Rather, it was Dr. Broukhim who had requested Dr. Moore's assistance. Since the process of ethics consultation is an ongoing process of dialogue and deliberation, as a matter of respect for the relationship between patient and physician as well as a matter of practicality, attempts to inform the attending physician should occur near the beginning of the consultation process, and whenever possible, before any conversation with the patient or family. The attending physician is the person ultimately responsible for the care of the patient and as such, he or she should be aware of matters that may affect the patient's care and disclosure of the patient's confidential information. Furthermore, the physician may have key information regarding any questions or issues that may have presented themselves. Notification is not the same as asking permission. In order to empower the moral agency of all persons involved in the ethical provision of care, individuals should feel that they can request a consult when they feel it is appropriate, without fearing retribution or having their concerns vetoed by the physician.

Although the narrative initially noted that Finder planned to discuss the case with the ICU staff as well as Dr. Broukhim, we are only told about the discussion with Dr. Broukhim. It is unclear if Finder intended to meet with the patient or clarify his role with the family. As a matter of general practice, one should always try to meet with the patient whenever possible. Ethics consultation is undertaken on behalf of a real person, not an abstract construct gleaned from written or oral accounts. Therefore, rather than relying on second or third-hand descriptions of the patient, it is a commendable aspect of practice to meet with the patient regardless of their decisional capacity or physical state in order to have an independent picture of their mental and physical circumstances. This is not only a matter of respect, it often yields surprising and useful information missing from the accounts of other persons.

In regard to clarifying Finder's role with Mrs. Hamadani and her family, opinion 9.115 of the AMA Code of Medical Ethics states that "in general, patient and staff informed consent may be presumed for ethics consultation" (AMA 2014). However, Mr. Zadeh, Mrs. Hamadani's son, had made clear his desire to not speak to the ethics consultant, Dr. Moore, or have him interact with the family any longer. There is no reason to presume that he intended, or would even agree to have, Finder replace Dr. Moore as the ethics consultant in his mother's case. When Mrs. Hamadani's daughter Nadira approaches Finder on the unit and invites him to meet her sister Farzana, the encounter appears primarily social, motivated by their gratitude for "making sure that Dr. Moore no longer is a bother to us" (Finder 2018: 32). Although Finder had begun his role as an ethics consultant on the case, he does not make this clear to the patient's daughters during their exchange in the patient's room. Under the guise of a social exchange, Finder asks them questions about their family, "mak- 
ing the choice to take advantage of what seemed to be an openness toward me that I wasn't sure existed, but if it did, I did not want to miss the opportunity it provided to learn more from Farzana and Nadira" (Finder 2018: 33). Ethics consultants can learn a great deal about the history and social dynamics of a family through casual conversation and observation, and in some situations this may be preferred over a formal interview-style of dialogue. Yet, the issue of informed consent looms large in this situation. Even though the patient's daughters freely exchange information with Finder regarding their family and their lives, one has to wonder if they would have been so forthcoming if they understood him to be gathering information based on his role as Dr. Moore's replacement.

As Finder "takes over" involvement with the family, his visits with the family exhibit features more in line with those of a supportive presence or respectful listener, rather than a facilitator or mediator of value conflicts or uncertainty. Yet, if a responsibility in clinical ethics consultation is to remain acutely aware of the multiplicity of power differentials inherent in social and clinical interactions, and to attempt to limit vulnerability or coercion in those interactions, then the mindful, nonjudgmental listening that formed the core of Dr. Finder's interactions with the family could be understood as a responsible starting point for any potential future moral engagement. This is especially true given the psychosocial dynamics associated with the patient's care. Despite clear and unvarying instructions regarding their wishes for CPR, the family repeatedly reacts to the perception that they were being pressured to make a different decision. Mr. Zadeh says "he did not visit, he simply came to get us to say what he wanted to hear," and at one point highlights feelings of discrimination, asking "Did Frank Sinatra's family have to have these conversations?" (Finder 2018: 26). Not all consultations require this type of supportive interaction to foster trust, however in this case respect for, or even tolerance of, the role of the ethicist to facilitate meaningful discussion regarding the ethical dimensions of the case had severely diminished.

Despite the appearance of the family's deeply held convictions, the patient's complex medical needs may at any time have led the family to have doubts or questions about their commitment to their stated goals and plans for the patient. Finder's continued supportive presence provided the family with a safe and meaningful forum to reflect upon any issues or concerns they may have had, in their own time, without exacerbating potential vulnerabilities they may have felt. With a strong possibility that the patient's clinical condition would warrant another contingent of decisions subjected to substantive critical examination, Finder's attempt to establish a relationship with the family addresses the fact that he was coming to the encounter as a stranger - a stranger who nonetheless had the power to engage in focused and critical questioning of the family's deeply held moral commitments. From the family's perspective, deeply delving into and analyzing their decisions may have seemed to yield only the potential for further psychosocial disruption with little concurrent upside. It is therefore appropriate, and perhaps desirable, to give the family the space and time to understand and adjust to both the current clinical picture and Finder. While it may leave the reader of the narrative yearning for Finder's more active engagement of the myriad ethical issues of the case, one could argue this sup- 
portive interaction with the family was a necessary foundation to what was, at the time, an unknown constellation of future events.

Despite these initial investigations and conversations, it is both surprising and worth noting that Finder fails to explicitly engage in other preparatory elements that one would expect to find, such as an exploration of what is known regarding the patient's wishes, her legal decision-maker, or any details that have come to light regarding the lived experience of her illness and family life.

\section{The Missing Patient}

The patient's autonomous right to participate in conversations about her care, and to make informed decisions about that care, has a long-standing history in American jurisprudence and medical ethics. It is therefore common for case reports in clinical ethics to begin and end with a focus on the patient and the patient's wishes and goals. When the patient lacks decisional capacity, the patient's wishes must be gleaned from past statements and/or expressed by a legally authorized proxy decision-maker. Mrs. Hamadani may be well-represented through the wishes and support of her family, yet the extent to which her family represents the patient's wishes remains unclear, as does the question if they represent her legal decisionmakers under state law. Many states limit the types of decisions that can be made by a patient's legal representative, or have restrictions based on what type of decisionmaker is providing the consent (such as power of attorney for healthcare, guardian, or a non-patient-designated individual). It is therefore important to better understand the broader ethical, legal and social context of the role of these decisionmakers and any limitations that may exist regarding decision-making.

Despite a narrative that in some respects covers 3 years of time, in "The Zadeh Scenario," Mrs. Hamadani never makes a first-person appearance. The silence of the patient's voice is distressing, not only because the right to consent to or refuse treatment lies with the patient (even when that right is executed on her behalf by a proxy decision-maker), but also because we have a sense that she may have been decisionally capable during significant portions of her treatment and thus able to participate in shared decision-making regarding her treatment and goals. She was, after all, still at home taking care of her husband (he had been diagnosed with dementia) - presumably not the act of a woman unable to make decisions. Over the course of her multiple hospitalizations did the physician, the ethics service, the palliative care service, or anyone else make an attempt to engage Mrs. Hamadani in advance care planning for her terminal illness? An explicit inquiry into and analysis of her values, her decisional capacity, her expressed or previously expressed wishes, her personal goals, or even the identity of the person she would choose as a proxy decisionmaker are lacking. Instead, there is only a reflected appearance viewed through the lens of her medical condition, reports of interactions with her family by the physicians and consultants, and a few reports of her history (not her wishes) provided by family members. Of course, some patients do not discuss their illnesses or 
express their wishes. It is especially at these times that the ethics consultant can be helpful to clinicians and family members in guided discussions to uncover and explore the patient's wishes based on past statements or personal preferences and disposition.

It is concerning that "The Zadeh Scenario" narrative fails to explicitly identify and analyze whose wishes are being expressed, instead focusing on the role of the patient's children in decision-making. For example, the case begins with the account that the patient's son, "Mr. Zadeh, and his sisters... found an oncologist who was willing to pursue aggressive treatments" (Finder 2018: 22) after his mother had been diagnosed 3 years ago. There is no mention if the patient had chosen to fight the illness with the support of her children, or perhaps that she had chosen to defer to her children's desire to get a second opinion. Going further, the original ethics consultation called by the neurologist cites the neurologist's belief that "the family's request for aggressive intervention" was inappropriate, and that the patient's son and daughters had shouted the physician out of the room and fired him (Finder 2018: 22, emphasis added). The rest of the Scenario reveals that physicians wanted assistance speaking with the family, that treatment decision meetings were held with the son and daughters, and the family was asked to make decisions regarding their mother's care (emphasis added). When Finder becomes involved, he appears to continue this trend. There is no mention of the patient's decisional capacity as he begins checking her chart and speaking with staff about the patient's medical condition. When he moves on to discuss with Dr. Moore the conversations Dr. Moore had with the patient's physicians, he does not ask about any interactions with the patient but wants to know "more about [Dr. Moore's] interactions with Mrs. Hamadani's children" (Finder 2018: 28).

Thus it is important that we do not know the patient's perception of her relationship with her children. The fact that the children are always present and express feelings of love does not necessarily mean that they had a healthy relationship from the perspective of the patient, or that they are protecting and advocating for the patient's wishes rather than operating out of a different set of complex emotions or cultural understandings. Certainly, it would have been ethically permissible for Mrs. Hamadani to request that decisions be made by her children, or even to request not to be a part of discussions about her care and treatment. However, by failing to mention any conversation with the patient during which the patient made such wishes for non-participation known, it is troubling that the case appears to presume that she did not wish to be involved in decision-making, or that her wishes were adequately represented by her children. What we are told is that the family is Persian, and there is a suggestion that cultural elements may "have been part of what was at play" (Finder 2018: 29). However, a commendable sensitivity to the patient's and family's cultural traditions would not justify a presumption that the patient wished to defer decision-making to her children or that she wished to entirely forgo any participation in discussions. As a result, the information we are given to reflect upon regarding what may constitute morally appropriate treatments or outcomes is questionable since it is the direct result of a different set of questions - what the care team feels 
is in her best interest, and the questions asked of the patient's family regarding their wishes regarding treatment decisions.

The distress of the patient's silence is compounded by the relative silence and stereotypical treatment of the patient's daughters. It is only the patient's son who is given a last name, is consistently referred to by his formal name "Mr. Zadeh," and who voices instructions to the care team in the narrative. While he appears to be well-supported by his sisters and there is no obvious discord between the family members, none of the female characters' opinions regarding treatment independent of Mr. Zadeh's interpretation are explored. Thus we cannot know if there was consensus among the patient's children regarding treatment or if they were unified in their understanding of their mother's wishes. Instead, the narrative never asks the question of whether Mr. Zadeh speaks for the family, and both the patient and her daughters form a silent chorus for Mr. Zadeh. In the absence of any discussion of the patient's views, her daughters' views, or of who is fulfilling the role of legal decision-maker, it is difficult to fully understand or contextualize the apparent moral premise that they were all on the same page regarding treatment. Are we to assume that the family's Persian identity necessarily entails a view that the female family members will defer to the male head of the family, or perhaps that even if there are family discussions happening behind the scenes that the male head of the family fully and sufficiently represents the views of the entire family to outsiders? Having cultural sensitivity does not mean that one should hold cultural stereotypes or fail to explore the unique nature of the family dynamics and relationships.

\section{What Is the Ethical Issue That Needs to Be Resolved?}

The role of ethics consultation is broad, from identifying and analyzing ethics concerns, facilitating communication, representing institutional policies, addressing knowledge gaps, integrating values into decision-making, and more. In this case, the focus of the meetings between care providers and the patient's family is on whether or not to provide CPR. The physician team seems to present a united front stating that the patient was not a candidate for further curative treatments, yet they also continue to offer those treatments and seem dismayed when the family chooses the treatments that are offered. Dr. Broukhim and Dr. Moore have specifically attempted to ensure that Mrs. Hamadani's children understand the ethical dimensions of the decisions that are being made, and Mrs. Hamadani's children have made it clear that they understand not only the clinical picture but also concerns about the patient's suffering. Weighing the information, the children have clearly communicated their decisions regarding treatment. Mr. Zadeh is consistent and clear that he wishes to pursue all available treatments "until her heart stops," (Finder 2018: 25), and "until the decision to act must be made" (Finder 2018: 31). Because the family is always at the bedside and thus available, it seems reasonable to assume they can fulfill their wish to make decisions only when decisions must be made, taking into account their mother's current clinical picture and the information 
provided by the clinical team. They have fulfilled their decision-making role by understanding the information presented to them, integrating their (and hopefully the patient's) values, and they have communicated their decisions regarding the clinical questions posed to them. There is not confusion about the clinical picture or what the family has decided and the team has concrete guidance on how to proceed. Finder points out that the case does not fall under the hospital's medically inappropriate treatment policy, and we are not presented with evidence the care being provided violates the patient's wishes or the standard of care. Finally, despite his reluctance, Dr. Broukhim appears willing to continue his care of the patient and follow the family's decisions. As a result, it seems that the issue of the patient's code status has been resolved, and the work that remains is helping the medical team understand and/or cope with the family's decisions.

I should note here that the impasse regarding code status may represent cultural differences in the meaning of time. Medical treatment plans at the end-of-life can be skewed toward anticipating what may happen and creating plans to address it. Forward-looking planning as a core value can be in opposition to a focus on the human interactions taking place in the moment and the desire to address decisions each in their own time. This is a tension between the desire to have time to prepare versus having time to spend interacting and expressing relationships. Certainly, we walk away from the narrative with an understanding that the family values spending time with their mother more than planning for her death.

Despite having an informed and clearly articulated plan of care, it is significant that the meetings in the narrative continue to focus on convincing the patient's children to make a different decision, rather than exploring the family's reasoning and goals for their mother. Changing the focus of conversations to create a better understanding of the family's reasons for their decisions may help care providers better accept having to act on a decision reflecting values that they do not appear to share. For example, while Dr. Broukhim may be prioritizing the minimization of perceived suffering, the patient's children may be prioritizing a different set of goals such as a duty to ensure they had fully explored every option for their mother or honoring their mother's wish to 'go down fighting.' In the same vein, discussions regarding their goals and what was motivating their reasoning process could also reveal powerful emotional states such as fear, guilt or grief which might be controlling their perceptions and choices.

Regardless, changing the focus of discussion to goals rather than procedures could help to create a more positive dialogue between all persons involved with the patient's care, even if the family does not change their mind regarding code status. A better understanding of the family's reasoning and motivations may also have helped the team better cope with or accept the family's decisions (the very point that Dr. Moore was pursuing when he was removed from the case).

A different issue represents another clear area of ethical concern. There are instances in the narrative where staff appear distressed during interactions with the patient's family, yet that distress is not explored in the narrative, nor are its potential solutions. Specifically, we are told "someone involved in her care-perhaps the consulting nephrologists or the ICU attending or the Social Worker" were con- 
cerned that Mrs. Hamadani was suffering (Finder 2018: 23). The perception that the patient is suffering is deeply concerning and deserving of further exploration. What do the persons involved mean by "suffering"? Were her symptoms poorly controlled, was she feeling depressed, or was she unsupported in pursuing her own goals? Was the source of the distress the perception that the family was poorly treating the staff who were caring for Mrs. Hamadani, or was it discomfort with the moral subjectivity that is inherent in end-of-life decisions? How are these issues being addressed by the Palliative Care service on this admission? These issues are clearly within the scope of the ethics consultation, yet we are not provided with an understanding of how suffering was being addressed or how such concerns were resolved. This may be a result of the hybrid assignment of ethics consultant duties, with Dr. Moore supporting the staff and other physicians and Finder supporting the family and working with Dr. Broukhim. In the end, the unresolved issues in the narrative regarding the staff's distress and perception that the patient was suffering seem to be clear ethical concerns that warrant the reasoned deliberation of the ethics consultant.

\section{Scope of Ethics Consultation}

"The Zadeh Scenario" presents several elements that raise questions about the scope of ethics consultation. Three such elements merit some explicit discussion: referrals, use of the electronic medical record to follow-up on patients, and the process of requesting an ethics consultation. In regards to referrals, during the initial ethics consultation 3 years ago, Dr. Moore solicited the involvement of a physician that would more closely align with the family's aggressive treatment goals: "In an effort to help this family, Steve was the one who had actually contacted Dr. Broukhim to see if he'd be willing to talk with Mr. Zadeh and his sisters" (Finder 2018: 22-3). This went beyond a mere recommendation regarding other available physicians which the family could choose or not choose to follow-up on. The consultant actually made the call himself based on his knowledge of Dr. Broukhim's reputation. Though it remains unclear how the recommendation came about and the process of consent that preceded the call, this action suggests pushing the bounds of clinical ethics consultation. One could be skeptical that the ethicist directly soliciting the new involvement of specific providers who best match the value-based goals of the patient/family is within the moral scope of the consultant's responsibility.

The use of the electronic medical record to track readmissions of patients who have previously been seen by the ethics consultation service shines a light on several questions: When does a consult end? Is follow-up to an ethics consultation part of continuity of care? Is the consultant part of the clinical team with a responsibility to the continuity of care? To be sure, the consultant is an actively engaged participant who serves a unique role as a facilitator and mediator in explicit discussions of values and beliefs which must be understood against a specific set of circumstances and relevant standards. As a practical endeavor, facilitating accountable and ethi- 
cally justifiable solutions means that as the clinical picture changes, so too may the ethically justifiable solutions. The ethics consultation detailed here provides a tangible example of intense value-laden discussions occurring over the course of an ethics consult. It further illustrates the fact that complex issues rarely become less complex merely because a plan of action is undertaken.

In his work with the patient/family and the health care providers over past hospitalizations, Dr. Moore has elicited and attended to the values, beliefs and judgments embedded in the activities and decisions of the patient's hospitalizations. How and why the beliefs and judgments of the stakeholders change over time can be morally significant, and because it can be difficult to capture all of the nuance or breadth of discussions in medical record documentation, it is often times the ethics consultant who is the repository and voice of those moral experiences. As the clinical situation changes, decision-making may require a return to those previous discussions, which now require new interpretations or application.

This does not mean, however, that ethics consultants have a moral responsibility to act everywhere a moral issue requires clarification. To do so runs the risk of obfuscating the moral responsibility of other staff. However, the ethical justification that grounds actions and plans of care can atrophy over time in the face of nearly constant turnover in care providers and institutional processes designed more toward standardization than individualization. In this case, Dr. Moore's continued involvement provides a stable point of contact and preserves the critical historical knowledge of those previous conversations and stages of understanding. While an electronic medical record that flags previous patients seen by the service upon their readmission involves important issues of privacy and confidentiality, as long as the patient/family were both aware of the consultant's potential involvement and did not object, this model of follow-up may be a salutary, if not always feasible practice.

In regards to the process of requesting an ethics consultation, we are told that during admissions following the initial consultation, Dr. Moore was "informally" asked by various staff members to "formally" intervene. The language of "informality' is worth noting. There are many ways that staff may experience moral moments while caring for patients. Some moral moments are experienced as a call to action while others may be experienced as self-reflection or moral distress. The ethics consultant can recognize, facilitate and affirm the complex emotions that may accompany these moments, but a line can and should be drawn between creating a safe space to discuss and examine moral feelings and a responsibility to follow-up and take action on issues uncovered during such discussions. Any person involved in the patient's care should have standing to call an ethics consult, but should do so within a formal process wherein the requestor takes responsibility for involving the ethics consultant, not just hope that the consultant will take the hint. A process of ethics consultation should lead to enhanced ethical understanding among the parties, but not rob stakeholders of their own ethical responsibility and moral agency. 


\section{Conclusion}

In conclusion, "The Zadeh Scenario" offers many important insights regarding the activities inherent in the process of ethics consultation. Nonetheless, we see that an account of the clinical engagement of a consultant is ultimately not enough to provide a holistic account of the consultant's practice, or to discern the core moral considerations that emerge among the divergent standpoints. Furthermore, much of the information that is needed to both understand and assess the role of the consultant, the goals of consultation, and the broader societal and legal context in which ethics consultations occur lies outside the parameters of a particular case - no matter how detailed or beautifully told.

\section{References}

American Medical Association (2014) Code of medical ethics of the American Medical Association Council on ethical and judicial affairs: current opinions with annotations, 2014-2015 edition. American Medical Association, Chicago

Finder SG (2018) The Zadeh scenario. In: Finder SG, Bliton MJ (eds) Peer review, peer education, and modeling in the practice of clinical ethics consultation: the Zadeh project. Springer, Cham, pp 21-42

Open Access This chapter is licensed under the terms of the Creative Commons Attribution 4.0 International License (http://creativecommons.org/licenses/by/4.0/), which permits use, sharing, adaptation, distribution and reproduction in any medium or format, as long as you give appropriate credit to the original author(s) and the source, provide a link to the Creative Commons license and indicate if changes were made.

The images or other third party material in this chapter are included in the chapter's Creative Commons license, unless indicated otherwise in a credit line to the material. If material is not included in the chapter's Creative Commons license and your intended use is not permitted by statutory regulation or exceeds the permitted use, you will need to obtain permission directly from the copyright holder. 